Eur. J. Clin. Chem. Clin. Biochem.

Vol. 31, 1993, pp. 477-489

(C) 1993 Walter de Gruyter \& Co.

Berlin . New York

\title{
Pathobiochemical Aspects of Cytoskeleton Components
}

\author{
By D. Kunze and B. Rüstow \\ Institute of Pathological and Clinical Biochemistry, Charité Hospital, Humboldt University Berlin
}

(Received October 6, 1992//February 3/May 13, 1993)

Summary: This review summarizes pathobiochemical aspects of diseases, in which cytoskeletal components play a crucial role in pathogenesis. An attempt to classify the disorders on the basis of phenotypic changes that occur in microfilaments, intermediate filaments and microtubuli was unsuccessful. Three groups of disorders are presented:

1. cytoplasmic inclusions in specific diseases (merely descriptive);

2. diseases with genetic defects in cytoskeletal proteins (a chain of causality from defect to phenotype, in some cases with large gaps);

3. diseases with suspected involvement of cytoskeleton (hypothetical causal chain).

Microfilaments are involved in certain pathogenetic processes on account of defects in their associated proteins; in Duchenne muscular dystrophy, dystrophin is defective, while the defective protein in Rett syndrome is synapsin. Defects in spectrin and membrane anchor proteins lead to disorders of the red cell membrane skeleton (congenital haemolytic anaemias). Intermediate filaments accumulate in some types of cytoplasmic inclusions, together with ubiquitin (Mallory bodies, desmin accumulation in some myopathies and others). A pathogenetic interpretation of this phenomenon is lacking. A genetic defect in certain types of keratin is the cause of epidermolysis bullosa. Interesting preliminary results are reviewed that reveal the crucial role of cytoskeletal components in a further group of diseases (intrahepatic cholestasis, Alzheimer disease, pemphigus). These disorders are currently under investigation, or are of theoretical interest with respect to the cytoskeleton. Specific reactions of cytoskeletal components in serum, which might be used diagnostically, have not been found.

\section{Introduction}

The cellular cytoskeleton, consisting of actin filaments, microtubules and intermediate filaments, is involved in many fundamental processes of the cell (see reviews 1-8). An ever increasing number of publications deals with variations of the cytoskeleton in disease. Literature on the morphological aspects of these disorders has been the subject of reviews, in which the affected proteins are listed in long tables (9,10 and others). Knowledge about the cytoskeleton and its disorders, collected by different disciplines from histology to biochemistry, would now seem to justify the present attempt to summarize the patho- biochemical aspects. Cytoskeleton research has revealed new cellular functions, and provided new pathobiochemical insights. The most recent example of this is the role of cadherins and desmosomes in cellcell interaction, and their involvement in the disturbances that occur in pemphigus, which are currently under investigation. On the other hand, new findings in cytoskeleton related diseases have implications for cell biology, the current example being the search for the function of dystrophin in striated muscle.

This generalized presentation represents an attempt to obtain a deeper insight by comparing and bringing together information in the cytoskeleton in different 
organs. Genetic deficiencies or anomalies of G-actin and tubulin, the main components of the cytoskeleton, have not been described in the literature, perhaps because they are lethal. Defects of actin- and tubulinassociated proteins, of spectrin, and of intermediate filaments are discussed in the present review. Reference is also made to the storage of intermediate filaments and ubiquitin in cytoplasmic inclusions and their relation to diseases. The review closes with a glance at clinical chemistry and the question of whether cytoskeletal components can be found in serum and if their determination may be of diagnostic importance.

\section{Proteins of the Cytoskeleton}

The term cytoskeleton includes 3 different structures which, like cellular organelles, subdivide cellular space: microtubuli $(11-18)$, intermediate filaments (5) and microfilaments $(3,6-8,14,15,20)$ (tab.1). These 3 organelles form a dense network, making contact with each other and other organelles $(21,22)$, especially the plasma membrane $(3,6,7,14,15,20)$ (actin filaments), while its extracellular components mediate cell-cell interaction $(1-3,14,15,23)$. Two properties of the cytoskeleton are responsible for its important role in cell biology. Firstly, in contrast to the permanency normally associated with a skeleton, the cytoskeletal filaments are not stable or static parts of the cell. Receptor mediated stimuli $(3,14,20)$ and other intracellular conditions $(\mathrm{Ca}, \mathrm{pH})$ lead to polymerisation or depolymerisation, to enlargement or reduction of the cytoskeletal network within seconds. The relation between monomers and polymers (normally $1: 1$ ) can be shifted very quickly. Secondly, actin filaments and microtubuli associate specific proteins (actin associated proteins: $(6,7,9,24)$; microtubuli associated proteins: $(4,11-13)$. A large number of these proteins modify the structure and properties of the filaments and link them with other structures and with the plasma membrane (tab. 1). The functional significance of the association of cytoplasmic enzymes with microfilaments is not yet clear $(25,26)$.

Microtubuli are normally long hollow tubes of proteins with an outer diameter of $25 \mathrm{~nm}$ (tab. 1) $(4,11$, $13,14)$. They are formed from molecules of tubulin, each of which is a heterodimer consisting of two tightly linked globular subunits ( $\alpha$ - and $\beta$-tubulin, $M_{\mathrm{r}}$ 50000 ). Each heterodimer binds 2 molecules of GTP. The polymer, i.e. the microtubule, is a polar structure with a plus (fast growing) and a minus (slow-growing) end. Special structures in the cell bind and stabilize microtubule ends. Most microtubules grow from the centrosome, which acts as a microtubule-organizing centre. $\gamma$-Tubulin, a newly identified member of the tubulin family, whose concentration in individual cells is extremely low $(16,17)$, is a universal component of microtubule organizing centres (mainly centrosomes) and it controls microtubule nucleation in vivo (18). The most prominent example of microtubule assembly is the mitotic spindle, which is affected by various drugs (colchicine, taxol, vinblastine). A large and everincreasing number of proteins, known as microtubuli associated proteins, interact and often colocalize with cellular microtubules. In the absence of well-defined functions for most of the microtubuli associated proteins known to date, they are usually classified according to their size (12). A special class of microtubuli associated proteins (kinesin, dynein) uses the energy of ATP hydrolysis to move unidirectionally along a microtubule, providing a mechanism for the spatial organisation and directed movements of organelles in the cytoplasm (27).

Intermediate filaments are $8-10 \mathrm{~nm}$ in diameter, which is "intermediate" between actin filaments and microtubules. They are formed from 4 types of fibrous polypeptides with a wide range of sizes $\left(M_{\mathrm{r}} 40000-\right.$ 130000) (tab. 1). All types share a similar central region which forms an extended $\alpha$-helix with three short interruptions $(5,19)$. The filaments are formed from a dimeric subunit by association with one another in large overlapping arrays. Intermediate filaments are extremely stable and there is not a large pool of unpolymerized intermediate filament proteins in the cell, as there is for actin and tubulin. The globular domains at either end allow the intermediate filament to vary in order to match the requirements of the particular cell type. The occurrence of different globular domains according to the cell type is so specific that they provide a distinctive "fingerprint", which is useful for tracing the origin of tumours.

Intermediate filaments are thought to protect cells against mechanical stress and to provide mechanical support to the cell and its nucleus. However, they differ in two functional aspects from actin filaments and microtubules. Firstly, they are relatively stable and more "skeletonlike". Secondly, their properties are determined by the amino-terminal and carboxylterminal domains of the intermediate filament, rather than by associated proteins.

The $M_{\mathrm{r}} 42000$ globular actin monomer (G-actin) has been highly conserved during evolution $(7,8)$. It has a bound nucleotide (ATP) which is hydrolysed to ADP on polymerization. Actin can be polymerized into double-helical actin filäments (F-actin), which usually contain up to a thousand G-actin molecules per filament. Polymerization is a very complicated 
Tab. 1. Components of the cytoskeleton.

\begin{tabular}{|c|c|c|c|}
\hline $\begin{array}{l}\text { Diameter of } \\
\text { the fibrils }\end{array}$ & $\begin{array}{l}\text { Actin filaments } \\
<8 \mathrm{~nm}\end{array}$ & $\begin{array}{l}\text { Intermediate filaments } \\
10 \mathrm{~nm}\end{array}$ & $\begin{array}{l}\text { Microtubules } \\
>20 \mathrm{~nm}\end{array}$ \\
\hline \multirow[t]{5}{*}{ Monomer } & G-Actin, $M_{\mathrm{r}} 42000$ & $\begin{array}{l}\text { Different according to } \\
\text { the cell type: }\end{array}$ & $\begin{array}{l}\text { Tubulin, } \alpha, \beta, \gamma \\
M_{\mathrm{r}} 2 \times 55000\end{array}$ \\
\hline & & $\begin{array}{l}\text { Epithelium: Keratin, } \\
M_{\mathrm{r}} 40000-70000\end{array}$ & \\
\hline & & $\begin{array}{l}\text { Muscle: Desmin, } \\
M_{\mathrm{r}} 50000-54000\end{array}$ & \\
\hline & & $\begin{array}{l}\text { Mesenchymal cells: } \\
\text { Vimentin, } \\
M_{\mathrm{r}} 42000-55000\end{array}$ & \\
\hline & & $\begin{array}{l}\text { Neurones: } \\
\text { Neurofilaments, } \\
M_{\mathrm{r}} 68000-160000- \\
210000 .\end{array}$ & \\
\hline
\end{tabular}

Associated Actin-associated (= AAP), differentiated according to the proteins main function (I) or typed as groups with a high degree of sequence homology in major protein families (II).

\section{I}

G-actin-sequestering proteins (Profilin). Actin filamentnucleating, end-blocking, and severing proteins (Gelsolin, Villin, Severin, $\beta$-Actinin)

F-actin-crosslinking proteins forming diff. network (Fodrin, Spectrin, Myosin) F-actin-crosslinking proteins forming bundles (Fascin, Fimbrin, $\alpha$-Actinin) Proteins linking F-actin to other structures (Spectrin, Vinculin)

Different enzymes (glycolysis)

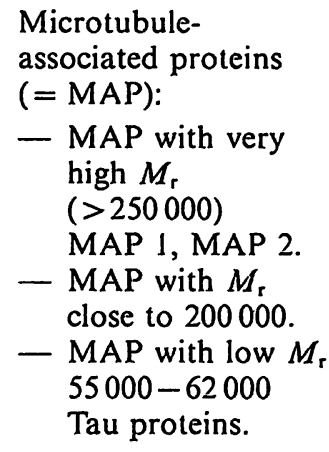

Microtubuleassociated proteins (= MAP):

- MAP with very high $M_{\mathrm{r}}$ $(>250000)$ MAP 1, MAP 2.

- MAP with $M_{\mathrm{r}}$ close to 200000.

- MAP with low $M_{\mathrm{r}}$ 55000-62000 Tau proteins.

Function

Cell motility, secretion, shape changes

Mechanical integration of cytoplasmic organelles, cell-cell adhesion
Formation of mitotic spindle, movement of cilia

Schematic drawing

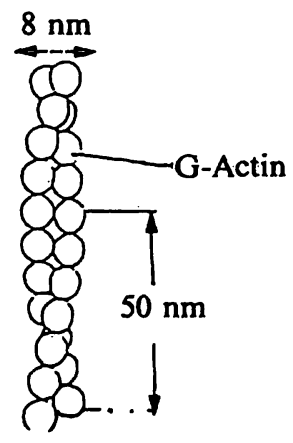

Dissociation of monomers at the barbed end
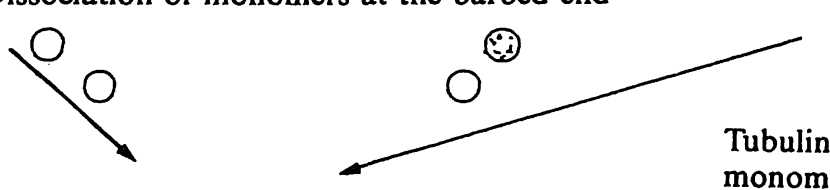

Association of monomers at the pointed end
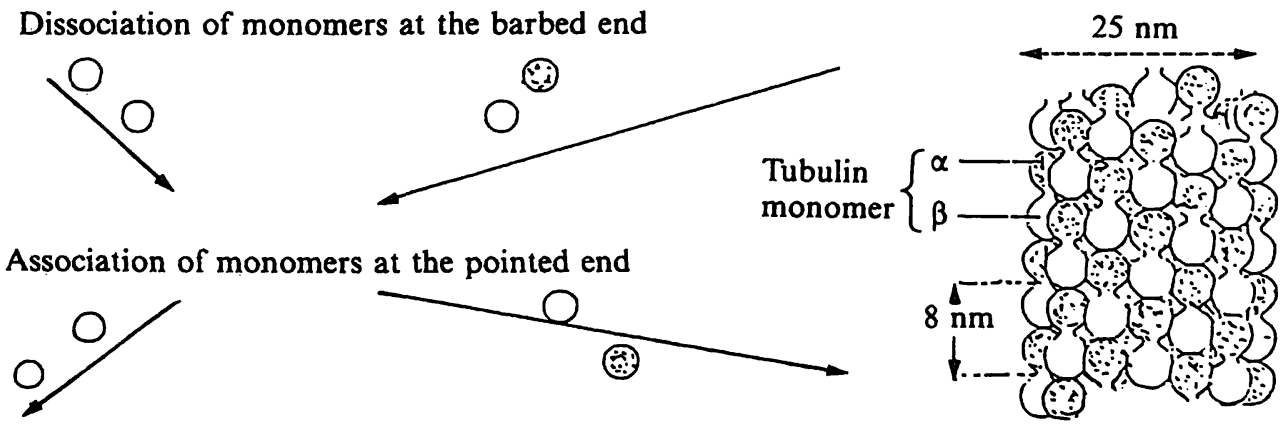

fast process with a balanced equilibrium between $G$ actin and actin filaments, depending on intracellular conditions such as the presence of actin binding proteins $(6,28)$; it is also influenced by certain drugs (cytochalasin, phalloidin) (29). In striated muscle, Factin (thin filaments) is involved in sarcomere structure, together with myosin (thick filaments), the regulatory proteins, tropomyosin and troponins $\mathrm{I}, \mathrm{T}$ and
C. The myosin/actin ratio is $1: 6$. In non-muscle cells this ratio is $1: 100$. Here also, the myosin filaments are oriented parallel to actin filaments, thus providing the biological substratum for a range of subcellular motility events (30). Movement occurs not only by the sliding filament mechanism as in muscle cells, but also by rapid assembly or disassembly of actin filaments, interactions between actin filaments them- 
selves, and between filaments and other proteins (2, 28). Thus specific interactions of either G- or F-actin with actin-associated protein determine the different molecular organisation and cellular locations of actin. In this way cellular functions dependent on subcellular motility are effected by microfilaments: endocytosis, exocytosis, secretion, movement of vesicles, internalization of receptor-bound material, and many Golgirelated activities $(6,28)$. Moreover, actin filaments play a role in the control of cell shape, in the regulation of the dynamics of the cytoplasmic matrix, and in intracellular cytoplasmic convection. Stress fibres are prominent features of the cytoskeleton of cultured cells, consisting mainly of actin with the minor components myosin, $\alpha$-actinin and tropomyosin (24). Gactin can be divided into 4 subdomains each responsible for binding specific actin associated proteins (DN-ase binding loop, hydrophobic loop and others) (8). Moreover, different cytoplasmic proteins (tab. 1) and enzymes, e.g. glycolytic enzymes $(25,26)$ and polysomes (22) are associated with actin filaments. A specific feature of actin filaments is their close connection with the plasma membrane, forming an especially dense network just beneath it which constitutes the cell cortex $(7,20)$. These concentrations can be mediated by direct coupling to phospholipids (31) or via linker proteins. Calpactins are such a group of proteins, displaying Ca-dependent binding to phospholipids and actin (32). Actin is one of the most abundant and therefore best studied eukaryotic proteins. Current knowledge of actin is reviewed in 1.c. $(6-8,14,15,20)$.

\section{Cytoplasmic Inclusions}

Several chronic human degenerative diseases $(33-50)$ show intracellular extralysosomal inclusions, containing intermediate filaments which can be demonstrated with immunohistochemical methods:

- desmin in cytoplasmic inclusions in special myopathies $(35,38-41)$,

- cytokeratins in Mallory bodies in alcoholic liver disease $(36,42-46)$,

- neurofilaments in the Lewy bodies in Parkinson disease $(47,48)$, neurofibrillary tangles in $\mathrm{Alz}$ heimer disease $(37,49)$, and Pick's body in Pick's lobar atrophy (34),

- glial fibrillary acidic protein and vimentin in $R o-$ senthal fibres in astrocytoma.

Most, if not all of the cytoplasmic inclusions that contain intermediate filaments also contain ubiquitin, a regulatory, highly conserved protein of 76 amino acids, which plays a role in the degradation of abnormal proteins $(51,52)$. Proteolysis by the ubiquitin system complements the lysosomal system and involves two discrete steps. Initially, in an ATP-dependent reaction, ubiquitin is covalently linked to the protein substrate. A single, destabilizing amino acid at the amino terminus facilitates the attachment of multiple copies of ubiquitin to specific lysine residues in the target protein. The protein moiety of the conjugate is subsequently degraded by an ATP-dependent protease with the release of free and reutilizable ubiquitin. Denatured or misfolded proteins and those containing otherwise abnormal amino acids are prefered substrates of ubiquitination $(44,53)$.

The pathobiochemical mechanisms of conjugation of intermediate filaments with ubiquitin is not understood. Lowe and coworkers $(33,34)$ suggested that two related but opposing processes occur in chronic degenerative diseases: the deleterious effects of the pathogenetic insult which can be chemical or viral, and a cellular cytoprotective response to the insult. Therefore, intermediate-filament-containing, ubiquitinated inclusions may be hallmarks of cellular attempts to eliminate pathogenetic insults by activating protein degradation mechanisms. According to this view, the formation of such inclusion possibly represents a secondary reaction to cell injury of many types, especially of neuronal aging. However, it is not clear whether the inclusion bodies are signs of increased, failed or defective proteolysis. Cytoplasmic inclusions are therefore very important as morphological-diagnostic signs but of little help in constructing a chain of pathogenetic events.

\section{Desmin and Cytoplasmic Inclusions in Myopathies}

Desmin is the intermediate filament of the muscle cell. Desmin filaments connect the edges of the Z-disc in striated muscle cells.

About forty different congenital myopathies are defined by clinical and morphological criteria. Three of them (central core disease, centronuclear myopathy, and nemaline/rod myopathy) regularly present with cytoplasmic inclusions containing accumulated desmin (38). Other myopathies or cardiomyopathies occasionally show inclusions of the desmin-type (35, 38).

Central core disease originally described by Shy \& Magee (39) obtained its name from the observation of discrete zones (cores) devoid of oxidative enzymes. This disorder selectively affects type I fibres and predisposes the carrier to malignant hyperthermia (38, 40). 
Nemaline or rod myopathy is an autosomal dominant trait showing clusters of small rod bodies, usually found in type I fibres near the Z-band and often in combination with it ((38), see 1.c. (40) for older literature).

Myotubular myopathy (41) is an autosomal recessive or X-linked recessive disease. The histologic abnormality led the authors to postulate an arrest of muscle fibre maturation at the myotubular (10-12 week) stage of embryogenesis $(38,40)$.

Clinically, all 3 myopathies show muscle hypotonia, and a non-progressive course is common. A neurogenic pathomechanism is likely, although the hereditary defect in all three myopathies is unknown (38, 40). Hence, the existence of inclusion bodies cannot be related to a common pathobiochemical cause. Conversely, knowledge of the composition of these inclusions has not helped the search for the pathobiochemical mechanism of the 3 myopathies.

\section{Keratin in Cytoplasmic Inclusions (Mallory Bodies)}

In 1911 Mallory described a peculiar hyaline degeneration of the cytoplasm of liver cells in patients dying with alcoholic cirrhosis (42). Identical hyaline material has been described in a diverse array of non-alcoholic liver diseases such as primary biliary cirrhosis, Wilson's disease, Indian childhood cirrhosis, chronic cholestasis, and even in extrahepatic locations such as the lung after exposed to asbestos, radiation and other forms of injury $(54,55)$. Mallory bodies can be produced in mouse hepatocytes by chronic griseofulvin intoxication (56). Because griseofulvin (like colchicine) causes microtubular depolymerization, a relationship between microtubules and Mallory bodies has to be assumed (see 1.c. (56) for review). Mallory body filaments consist of cytokeratin. Keratins are divided into 2 subclasses: 11 acidic (type I) keratins and 8 neutral to basic (type II) keratins. Intermediate filaments are formed from equimolar amounts of type I and type II keratin $(5,19)$. Mallory bodies contain cytokeratins with very high molecular masses, so that a posttranslational modification may be involved in Mallory body pathogenesis (36). Mallory bodies also contain ubiquitin (44) and different polypeptides (36, $45,46)$. They have been subdivided into 3 morphological types representing different stages in their evolution (43). The formation of Mallory bodies is accompanied by derangement and even loss of the keratin cytoskeleton of hepatocytes. This is perhaps the result of the accumulation of keratin in Mallory bodies $(45,46)$. They can also be observed in cholestasis (57).

\section{Neurofilaments in Cytoplasmic Inclusions}

Neurofilament proteins are characteristic for neuronal cells. They accumulate in the Lewy bodies in Parkinson disease $(47,48)$, as Pick bodies in Pick's lobar atrophy and as neurofibrillar tangles in Alzheimer disease $(37,49,50,58,59)$. Their appearance is not specific for the 3 diseases and seems to reflect a neurodegenerative disorder. Obligate components of the 3 inclusions are neurofilaments and ubiquitin, but many other components are involved and the literature is full of observations obtained by immunohistochemical methods.

\section{Glial Fibrillary Acidic Protein in Cytoplasmic Inclusions}

Glial fibrillary acidic protein is the intermediate filament of glial cells (astrocytes and some Schwann cells). Cytoplasmic inclusions are described as Rosenthal fibres in astrocytoma (together with vimentin as a minor component) (60).

Vimentin is the intermediate filament of mesenchymal cells (see review (61)). A pathobiochemical relationship between vimentin and specific diseases has not been established. Another intermediate filament is nuclear lamin, but it has not been implicated in specific diseases.

\section{Disorders of Red Cell Membrane Skeleton: \\ Hereditary Spherocytosis and Elliptocytosis}

The cytoskeleton of the erythrocyte has a specialized composition $(3,7,14,62,63)$. The main component is spectrin, a stable dimer of two chemically distinct peptides ( $\alpha$-chain, $M_{\mathrm{r}} 240000, \beta$-chain, $M_{\mathrm{r}} 220000$ ), which are oriented in parallel and intertwined. The dimer contains rather rigid helical domains separated by flexible regions composed of highly hydrophobic domains. The dimers associate end to end forming a tetrameric protein of $200 \mathrm{~nm}$ length. The tails of the tetramers bind to actin oligomers which are 12-14 monomers long. The actin oligomers form the nodes of the network. Every node binds an average of 5 spectrin tetramers, and the association is strengthened by band 4.1 proteins (fig. 1) $(64,65)$.

The cytoskeletal network is attached to the membrane by at least two proteins: ankyrin and protein 4.1. Ankyrin binds simultaneously to the $\beta$-spectrin subunit and to the cytoplasmic N-terminal domain of the anion transporter (= band 3 protein). Protein 4.1 interacts with glycophorin $C$, the major sialoglycoprotein. Many other proteins are involved in this 
a) Cross section

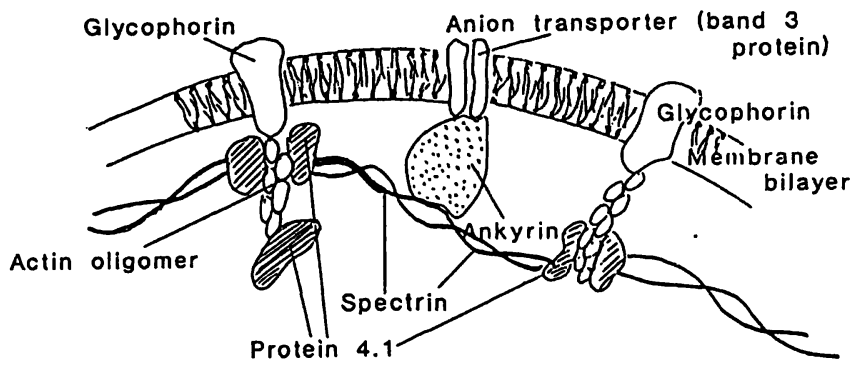

b) Spectrin meshwork with hexagonal lattice

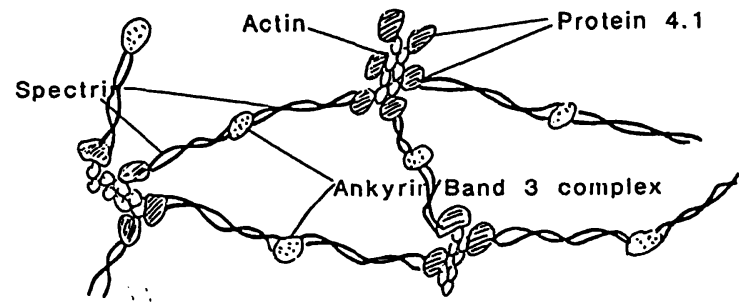

Fig. 1. Schematic model of human red blood cell cytoskeleton according to Byers \& Branton, Liu et al:

a) Cross section: modes of interaction of cytoskeletonassociated proteins with intrinsic membrane proteins. The cytoskeleton is anchored by ankyrin and band 3 protein and at the cross points by the complex actin, protein 4.1 and glycophorin to the erythrocyte membrane.

b) Spectrin meshwork with hexagonal lattice linked by junctional complexes to the membrane.

network. A schematic presentation is shown in figure 1. The red blood cell cytoskeleton has been the subject of many authoritative reviews $(3,7,14,62,63)$.

The erythrocyte cytoskeleton is a major determinant of membrane shape and flexibility and helps to control lipid organisation and mobility, and the topography of integral proteins. Plastic deformation of red blood cells is probably due to realignment of dynamic skeletal interactions in response to the stress of distortion. Defects in the network permit membrane budding and fragmentation (66) and, in the most extreme cases, result in a spherical shape of the erythrocyte comparable to that of isolated phospholipid vesicles.

Today it is clear that three red cell disorders characterized by shape changes are caused by defects of membrane cytoskeletal components. These 3 anaemias are: hereditary spherocytosis, hereditary elliptocytosis, and hereditary pyropoikilocytosis.

The characteristic erythrocyte shape in hereditary spherocytosis is the spherocyte: a cell with decreased surface area per unit volume (mean corpuscular vol= ume is usually normal, mean corpuscular haemoglobin concentration is increased to between 350 and 380 $\mathrm{g} / \mathrm{l})$. Many metabolic abnormalities have been iden- tified in hereditary spherocytosis red cells, but except for the cytoskeleton variations, the majority are believed to be secondary. Erythrocyte membranes from almost all hereditary spherocytosis patients are spectrin-deficient. The mechanism is under debate (67). The condition presents a clinically broad picture, extending from neonatal hereditary spherocytosis in the form of jaundice with poor prognosis in the first few days of life, to cases of compensated haemolysis, in which red cell production and destruction are balanced. In view of this heterogeneous presentation, the genetic defect of spectrin may exist at different genetic loci. Furthermore, spectrin deficiency is often combined with defects of intrinsic membrane proteins (67, 68).

In hereditary elliptocytosis the defect lies in the skeletal proteins, usually as a combination of a spectrin abnormality and a deficiency of an intrinsic membrane protein. Partial transition to spherocytosis with splenic conditioning is observed only in very severe cases (for review see 1.c. (69)).

The thermic abnormality of spectrin leads to hereditary pyropoikilocytosis. Hereditary pyropoikilocytosis is thought to be related to hereditary elliptocytosis, since both have been reported in the same family (69). Hereditary pyropoikilocytosis is a rare disorder characterized by bizarre-shaped microcytic cells (for review see 1.c. (69)).

Although this is an oversimplification, the 3 hereditary haemolytic anaemias are presented together in table 2 . In nearly all cases a defect/deficiency of spectrin is basic to the condition, combined with a deficiency of an anchor membrane protein. The clinical and genetic picture is particularly broad in the subtypes of hereditary elliptocytosis. In all cases haemolysis is markedly ameliorated by splenectomy. However, the specific pathobiochemical mechanism(s) responsible for splenic sequestration and red cell destruction remains to be defined.

\section{Epidermolysis Bullosa}

Epidermolysis bullosa involves a clinically and pathogenetically heterogeneous group of disorders characterized by trauma-induced blistering of the skin. Usually epidermolysis bullosa is classified as epidermolysis bullosa simplex, junctional epidermolysis bullosa, or dystrophic epidermolysis bullosa according to the blister site observed in electron microscopy (70). In epidermolysis bullosa simplex the split in blister formation is within the basal cells of the epidermis, such that the base of the blisters contains remnants of the basal plasma membrane and the top 
Tab. 2. Hereditary defects of the red cell membrane skeleton.

\begin{tabular}{|c|c|c|c|}
\hline . & $\begin{array}{l}\text { Hereditary } \\
\text { spherocytosis }\end{array}$ & $\begin{array}{l}\text { Hereditary } \\
\text { elliptocytosis }\end{array}$ & $\begin{array}{l}\text { Hereditary } \\
\text { pyropoikilocytosis }\end{array}$ \\
\hline \multicolumn{4}{|l|}{$\begin{array}{l}\text { Congenital haemolytic anaemia (dominant } \\
\text { or recessive) with: }\end{array}$} \\
\hline $\begin{array}{l}\text { 1. Deficiency of spectrin. Speculations: } \\
\text { - biosynthesis diminished } \\
\text { - biosynthesis of an unstable spectrin } \\
\text { - binding of spectrin at the membrane } \\
\text { insufficient }\end{array}$ & $\begin{array}{l}+ \\
\text { (Correlates with the se- } \\
\text { verity of the disease) }\end{array}$ & $\begin{array}{l}+ \\
\text { (Frequent structural de- } \\
\text { fect with diminished self } \\
\text { association) }\end{array}$ & $(+)$ \\
\hline $\begin{array}{l}\text { 2. Defects of membrane proteins (protein } \\
4.1 ., \text { glycophorin } C \text { ) }\end{array}$ & + & + & + \\
\hline \multirow{2}{*}{$\begin{array}{l}\text { 3. Thermal sensitivity of spectrin (normal } \\
\text { spectrin denatures in } 10 \text { min at } 49^{\circ} \mathrm{C} \text {, red } \\
\text { cells fragment at this temperature) }\end{array}$} & - & $-\rightarrow+$ & + \\
\hline & & \multicolumn{2}{|c|}{ Purified spectrin denatures in $10 \mathrm{~min}$ at $45^{\circ} \mathrm{C}$} \\
\hline 4. Splenic conditioning & $\begin{array}{l}+ \\
\text { Progressive loss of mem- } \\
\text { brane surface and decrease } \\
\text { of surface to volume ratio } \\
\downarrow \\
\text { Hereditary spherocytosis } \\
\text { cells become increasingly } \\
\text { spheroidal } \\
\downarrow\end{array}$ & - & - \\
\hline 5. Destruction in the spleen & + & + & + \\
\hline
\end{tabular}

contains the nucleus and supranuclear portion of the basal cell. In junctional epidermolysis bullosa the split is within the basement membrane zone in the lamina lucida. In the very severe dystrophic epidermolysis bullosa (in most cases the fourth decade of life is not survived) the split is in the upper dermis.

The apparently uniform clinical picture of epidermolysis bullosa should be further differentiated by taking into account pathobiochemical results. In dystrophic epidermolysis bullosa the structures known as anchoring fibrils are affected; since the major constituent of anchoring fibrils is collagen VII, dystrophic epidermolysis bullosa is probably a collagenosis ( 70 , 71, 72).

Epidermolysis bullosa simplex and junctional epidermolysis bullosa are different phenotypes of an autosomal dominant heredited keratin defect $(71,72)$, although epidermolysis bullosa simplex is also manifested in several subtypes, named after the first authors to describe them (Weber-Cockayne, Köbner, Dowling-Meara).

The genes encoding the type I keratins are on chromosome $17 \mathrm{q}$, those encoding type II on chromosome $12 q(70)$. Of the many possible heterodimers, at least 20 are found in different layers of skin epithelium, and another 8 in hair and nail. The localisation of the mutation determines the clinical presentation.

\section{Duchenne Muscular Dystrophy}

Duchenne muscular dystrophy is a fatal progressive myopathy affecting approximately 1 in 3000 boys. It is an X-linked recessive disorder and is allelic to Becker muscular dystrophy, a less severe and less frequent condition. In 1988 a protein called dystrophin was identified as the defective protein in Duchenne muscular dystrophy by the research groups of Koenig, Monaco, Kunkel and Hoffman (73-78). Dystrophin is a very large protein $\left(M_{\mathrm{r}} 427000\right)$ present in healthy muscle $(0.002 \%$ of total proteins in muscle). Extremely small quantities are also found in heart and brain. Amino acid sequence homologies with actinin and spectrin and structural analysis led to the conclusion that dystrophin is a cytoskeletal protein (74-77). It consists of 4 domains. The $\mathrm{N}$-terminal domain with 240 amino acids is highly homologous to cytoskeletal $\alpha$-actinin. The $\mathrm{N}$-terminal domain is linked to a large rod-like domain with 24 repeats of 109 amino acids, which resembles the repeat domains of spectrin and $\alpha$-actinin. Spacer sequences which do not align with the repeat consensus are present at the 
beginning and the end of the domain. The high proline content of the spacers suggests that they represent hinges (78). The next domain is cysteine-rich and is related to the $\mathrm{C}$-terminus of $\alpha$-actinin. The $\mathrm{C}$-terminal domain contains 420 amino acids and does not match with any other previously characterized proteins. Using different antibodies, dystrophin was shown to be localized at the cytosolic face of the sarcolemma in normal myotubes (79).

Duchenne muscular dystrophy muscle tissue showed no immunoprecipitation with antibodies against dystrophin, while muscle tissue from the mild BeckerKiener dystrophy showed an incomplete precipitation zone with gaps (80).

The central problem of topical Duchenne muscular dystrophy research has been to relate the defect of this metabolically inert cytoskeletal protein to the various metabolic disorders which accompany the disease. In the current model of pathogenesis, dystrophin protects the surface membrane of the myotubule from pleating charges $(78,79)$. The absence of dystrophin in Duchenne muscular dystrophy leads to lesions of the surface membrane resulting in Ca-influx with subsequent activation of $\mathrm{Ca}$-dependent phospholipases and proteinases.

Further evidence for the relationship between dystrophin and metabolism is provided by the results of Ervasti et al. (81). They showed that the localization of dystrophin at the cytoplasmic face of the sarcolemma results from a tight association of dystrophin with an integral membrane protein consisting of 4 glycoproteins (82). The concentration of one of these is greatly reduced in Duchenne muscular dystrophy muscle. Thus, the absence of dystrophin may lead to the loss of a dystrophin-associated glycoprotein. This phenomenon is paralleled in elliptocytotic erythrocytes, where the absence of cytoskeletal proteins is accompanied by a loss of surface membrane components (splenic conditioning) (66). It was speculated that the lost glycoprotein in dystrophic muscle might play a role in the regulation of intracellular $\mathrm{Ca}$ (81).

Besides the ambiguities in the relation between dystrophin and Duchenne muscular dystrophy metabolism, there are other uncertainties. Dystrophin is also absent in animal forms of dystrophy such as xmd dogs, mdx mice and a genetic form in cats. In all these models the disease takes a very benign course. $\mathrm{Mdx}$ mice do not have a shortened life expectation (reviewed in 1.c. (83)). Furthermore, dystrophin is also found in brain (84) and heart $(85,86)$, but in Duchenne muscular dystrophy these two organs show not obligatory symptoms.

\section{Rett Syndrome}

The Rett-syndrome is an X-linked neurodegenerative disorder whose heredity is not clear $(87,88)$. Because Rett syndrome is found in females only, a new Xchromosomal mutation with embryonic lethality for males is thought to exist. Recently, about 1000 cases have been published. The disease takes a progressive course with extrapyramidal disorders and atrophy of the brain.

Circumstantial evidence suggests that a defect in synapsin I gene structure or expression might be involved in Rett syndrome $(87,88)$. This evidence includes analysis of structural and functional aspects of synapsin I primary structure, and characterization of synapsin I messenger RNAs.

Synapsin I is a neuron-specific phosphoprotein. In a phosphorylation-dependent process, it binds to small synaptic vesicles and actin-filaments, and becomes localized on the cytoplasmic surface of the vesicles. It has been hypothesized that dephosphorylated synapsin I inhibits neurotransmitter release by anchoring the synaptic vesicles to the actin filaments of the nerve terminal (89). There seem to be 2 pools of transmitter in the presynaptic nerve terminal, one associated with actin filaments, the other representing a "free" pool which is available for release. The size of these pools is thought to be regulated by the reversible phosphorylation of synapsin I through various signal transduction pathways.

\section{Alzheimer Disease}

Alzheimer disease is the most common form of adultonset dementia and approximately $10 \%$ of the population over the age of 65 are affected (e.g. $(91,92)$ ). The major problem for research on the aetiology of this condition is its clinical heterogeneity; it may present as a familial early-onset, familial late-onset, or sporadic form. The literature on the pathobiochemical aspects of Alzheimer disease is enormous (for reviews see 1.c. $(49,58,91-95))$. Much effort has been devoted recently to elucidation of the causal chain linking the amyloid precursor protein (a product of chromosome 21) via $\beta / A 4$ protein to the Alzheimer amyloid deposit. Cytoskeleton is involved because neurofibrillary tangles are found as paired helical filaments containing microtubules, neurofilaments, ubiquitin and (abnormal) phosphorylated tau-protein $(37,50)$. It is not yet known how and why they occur. This finding is not specific for Alzheimer's disease and may be observed in some neurodegenerative disorders. 
Iqbal and coworkers place the abnormalities of the cytoskeleton at the centre of their hypothesis (9395). They revealed a microtubule assembly defect in the brain of Alzheimer patients taken immediately after death. The quantity of tubulin was normal and isolated tubulin showed the same assembly behaviour as in controls (94). They concluded that the defective assembly is due to the abnormal phosphorylation of tau-protein. Tau protein is reversibly phosphorylated and regulates the assembly and dissambly of microtubules. It is hypothesized that abnormal phosphorylation together with other modifications might stabilize tau-protein so that it becomes a component of neurofibrillary tangles. Because microtubules are thought to be required for axoplasmic flow (possibly as vesicles with dynein and kinesin as motors) any obstruction of this flow will lead to neurofibrillary lesions and a disturbed neurotransmission (94-96).

However, in Alzheimer disease the neuronal cytoskeleton is severely affected. It remains to be established whether or not the cytoskeleton defect is a primary factor.

\section{Desmosomes and Skin Defects in Cell-Cell Contact: Pemphigus Vulgaris and Bullous Pemphigoid}

Pemphigus vulgaris and bullous pemphigoid are fatal skin diseases in which autoantibodies against protein components of desmosomes or hemidesmosomes cause loss of cell-cell adhesion, with resultant epidermal blisters. Desmosomes are junctions involved in intercellular adhesion of epithelial cells, whereas hemidesmosomes anchor epithelial cells to the basal lamina. Both are characterised at the ultrastructural level by dense cytoplasmic plaques. They are composed of a mixture of intracellular attachment proteins called desmoplakins, and tightly associated with a thick network of keratin filaments $(97,98)$ which pass along the surface of the plaque. Transmembrane linker glycoproteins called desmogleins bind to the plaques and interact through their extracellular domains to hold the adjacent membranes together by a Ca-dependent mechanism (cadherins). Autoantibodies reactive with the special desmosomal cadherins, desmoglein I and desmoplakin I, have been found in pemphigus foliaceus (97-99) and pemphigus vulgaris $(100,101)$, respectively, and obviously play a causal pathogenetic role. The protein targets of bullous pemphigoid (cell adhesion to the basement membrane is affected) autoantibodies are diverse $(102-104)$. Because multiple antigens are recognized by bullous pemphigoid sera, care must also be taken in assigning them to a subcellular location. Nevertheless, the action of antibodies against one or more of the desmosomal linker glycoproteins, leading to disruption of desmosomes between skin epithelial cells, is the immediate cause of blistering. The antibodies disrupt desmosomes only in skin, suggesting that desmosomes in other tissues may be biochemically different.

\section{Bile Secretion and Intrahepatic Cholestasis}

The term cholestasis indicates that defects in secretion of bile may be due not only to mechanical obstruction but also to abnormalities in the secretory function of liver cells (105). All 3 types of cytoskeletal filaments are involved in the secretion process. Morphological studies have revealed alterations of canalicular cytoplasm, in particular the cytoskeletal elements such as microfilaments (106). Later pathobiochemical and pharmacological evidence indicates the involvement of the cytoskeleton in cholestasis. The search for the pathogenesis of cholestasis has moved from the bile duct to the hepatocyte. The cholestasis induced by cytochalasin B (106) and chronic administration of phalloidin (107) have gained widespread popularity as experimental models. Cytochalasin treatment affects actin filaments and leads to a dilatation of canaliculi, loss of microvilli and inhibition of taurocholate transport. Phalloidin administration increases $F$-actin around the canaliculi and the number of tight junctions. It disorders the motility of the canaliculi (107). The familial cholestasis observed in North American Indian children has been interpreted as a microfilament dysfunction with a molecular defect in hepatocyte actin or actin associated proteins (108). On the other hand, bile acids inhibit the polymerisation of actin in vitro (109). Thus, the question arises as to the nature of the primary event: an increased level of bile acids or defective actin filaments?

Theoretical reasoning also suggests an important role for actin filaments in bile secretion. Thus, canalicular contractions have been observed, which may be caused by pericanalicular actin/myosin filament interactions $(55,107,110)$. Furthermore, the cellular polarization and the positioning and organisation of the attachment to the neighbouring cell or lumen is an important factor in hepatocyte function. This is mainly regulated by the cytoskeleton (55).

An involvement of intermediate filaments in cholestasis is also shown by formation of Mallory bodies. In contrast to their localisation in alcoholic liver disease, in cholestasis they are found preferentially in the periportal area (see l.c. (54)).

Colchicine, an inhibitor of tubulin polymerization, decreases bile salt excretion (111). Biliary lipid secretion involves the exocytosis of vesicles consisting 
mainly of phospholipid and cholesterol $(112,113)$. Bile acids induce the microtubule-dependent bile and lipid secretion, whose biochemical mechanism is poorly understood $(113,114)$.

Future research will no doubt reveal the nature of the pathogenetic involvement of the cytoskeleton in such fatal diseases as primary biliary cirrhosis.

\section{Clinical Chemistry of Cytoskeletal Components}

Cytoskeletal proteins have not been found in serum. Among the cytoskeleton associated proteins only gelsolin, a G-actin binding protein has been found in blood. Plasma gelsolin, present at $>200 \mathrm{mg} / \mathrm{l}$, may have a protective function by promoting the clearance of actin filaments released during tissue injury. Muscle may be the predominant secretory source (115). An increased plasma gelsolin concentration has also been reported in haemolysis (116). Actin-gelsolin com-

\section{References}

1. Turner, C. E. \& Burridge, K. (1991) Transmembrane molecular assemblies in cell-extracellular matrix. Curr. Opin. Cell Biol. 3, 849-853.

2. Wang, Y. L. (1991) Dynamics of the cytoskeleton in live cells. Curr. Opin. Cell Biol. 3, 27-32.

3. Luna, E. J. (1991) Molecular links between the cytoskeleton and membranes. Curr. Opin. Cell Biol. 3, 120-126.

4. Matus, A. (1990) Microtubule-associated proteins. Curr. Opin. Cell Biol. 2, 10-14.

5. Robson, R. M. (1989) Intermediate filaments. Curr. Opin. Cell Biol. 1, 36-43.

6. Pollard, T. D. \& Cooper, J. A. (1986) Actin and actinbinding proteins. A critical evaluation of mechanisms and functions. Annu. Rev. Biochem. 55, 987-1035.

7. Mangeat, P.-H. (1988) Interaction of biological membranes with the cytoskeletal framework of living cells. Biol. Cell 64, 261-281.

8. Bremer, A. \& Aebi, U. (1992) The structure of the F-actin filament and the actin molecule. Curr. Opin. Cell Biol. 4, $20-26$.

9. Dustin, P. \& Brion, J. P. (1988) Quelques aspects de la pathologie du cytosquelette. Ann. Pathol. 8, 3-19.

10. French, S. W., Okanoue, T., Swierenga, S. H. \& Marceau, N. (1987) The cytoskeleton of hepatocytes in health and disease. Monogr. Pathol. 28, 95-112.

11. Avila, J. (1990) Microtubule dynamics. FASEB J. 4, $3284-3290$.

12. Wiche, G. (1989) High-M $M_{r}$ microtubule-associated proteins: Properties and functions. Biochem. J. 259, 1-12.

13. Soifer, D. (1986) Factors regulating the presence of microtubules in cells. Ann. N. Y. Acad. Sci. 466, 1-7.

14. Carraway, K. L. \& Carraway, C. A. C. (1989) Membranecytoskeleton interactions in animal cells. Biochim. Biophys. Acta 988, 147-171.

15. Niggli, V. \& Burger, M. M. (1987) Interaction of the cytoskeleton with the plasma membrane. J. Membrane Biol. 100, 97-121.

16. Oakley, B. R., Oakley, C. E., Yoon, Y. \& Jung, M. K. (1990) Gamma-tubulin is a component of the spindle pole body that is essential for microtubule function in Aspergillus nidulans. Cell $61,1289-1301$. plexes are formed in blood (117). None of these blood components is diagnostically useful.

Cerebrospinal fluid of patients with neuropathies has been investigated for the presénce of glial fibrillary acidic protein (118). Although the protein is found in cases of severe ischemic brain damage, this finding has no known diagnostic significance $(118,119)$.

A large number of publications deals with the occurrence of antibodies against cytoskeletal proteins. Autoimmune diseases, reactions after organ transplantation, and connective tissue diseases have been studied extensively. Specific relationships and diagnostically useful data have, however, not been reported.

\section{Acknowledgement}

The authors thank Michael Schlame for critical reading of the manuscript. Due to limitations of space, review literature is often cited rather than original publications. We apologize to all those colleagues whose publications are not cited.

17. Zheng, Y., Jung, M. K. \& Oakley, B. R. (1991) Gammatubulin is present in Drosophila melanogaster and Homo sapiens and is associated with the centrosome. Cell 65, $817-823$.

18. Joshi, H. C., Palacios, M. J., McNamara, L. \& Cleveland, D. W. (1992) Gamma-tubulin is a centrosomal protein required for cell cycle-dependent microtubule nucleation. Nature 356, 80-83.

19. Skalli, O. \& Goldman, R. D. (1991) Recent insights into the assembly, dynamic, and function of intermediate filament networks. Cell Motil. Cytoskeleton 19, 67-79.

20. Burn, P. (1988) Amphitropic proteins, a new class of membrane proteins. TIBS $13,79-83$.

21. Hesketh, J. E. \& Pryme, I. F. (1991) Interaction between mRNA, ribosomes and the cytoskeleton. Biochem. J. 277, $1-10$.

22. Zambetti, S., Wilming, L., Fey, E. G., Penman, S. \& Stein, J. (1992) Differential association of membrane-bound and non-membrane-bound polysomes with the cytoskeleton. Exp. Cell Res. 191, 246-255.

23. Solursh, M. (1989) Extracellular matrix and cell surface as determinants of connective tissue differentiation. Am. J. Med. Genet. 34, 30-34.

24. Lazarides, E. and Weber, K. (1974) Actin antibody: the specific visualization of actin filaments in non-muscle cells. Proc. Natl. Acad. Sci. USA 71, 4742-4746.

25. Roberts, S. J. \& Somero, G. N. (1989) Properties of the interaction between phosphofructokinase and actin. Arch. Biochem. Biophys. 269, 284-294.

26. Masters, C. (1984) Interactions between glycolytic enzymes and components of the cytomatrix. J. Cell Biol. 99, $222 \mathrm{~S}=225 \mathrm{~S}$

27. Vale, R. (1987) Intracellular transport using microtubulebased motors. Annu. Rev. Cell Biol. 3, 347-378.

28. Weeds, A. (1982) Actin binding proteins - regulators of cell architecture and motility. Nature $296,811-816$.

29. Cooper, J. A. (1987) Effects of cytochalasin and phalloidin on actin. J. Cell Biol. 105, 1473-1478.

30. Korn, E. D. \& Hammer, J. A. (1988) Myosins of nonmuscle cells. Ann. Rev. Biophys. Chem. 17, 23-45. 
31. St-Onge, D. \& Gioquaud, C. (1990) Research on the mechanism of interaction between actin and membrane lipids. Biochem. Biophys. Res. Comm. 167, 40-47.

32. Klee, C. B. (1988) $\mathrm{Ca}^{2+}$-dependent phospholipid- (and membrane-) binding proteins. Biochemistry 6, 66456653.

33. Mayer, R. J., Lowe, J. \& Landon, M. (1991) Ubiquitin and the molecular pathology of chronic degenerative diseases. J. Pathol. 163, 279-281.

34. Mayer, R. J., Lowe, J., Lennox, G., Doherty, F. \& Landon, M. (1989) Intermediate filaments and ubiquitin: a new thread in the understanding of chronic neurodegenerative diseases. Prog. Clin. Biol. Res. 317, 809-818.

35. Schroder, J. M., Sommer, C. \& Schmidt, B. (1990) Desmin and actin associated with cytoplasmic bodies in skeletal muscle fibers. Acta Neuropathol. Berl. 80, 406-414.

36. Zatloukal, K., Böck, G., Rainer, I., Denk, H. \& Weber, K. (1991) High molecular weight components are main constituents of Mallory bodies isolated with a fluorescence activated cell sorter. Lab. Invest. 64, 200-206.

37. Godman, J. E. \& Yen-S., H. (1986) Cytoskeletal protein abnormalities in neurodegenerative diseases. Ann. Neurol. 19, 209-223.

38. Goebel, H. H. (1991) Congenital myopathies. Acta Paediatr. Jpn. 33, 247-255.

39. Shy, G. M. \& Magee, K. R. (1956) A new congenital nonprogressive myopathy. Brain 79, 610-621.

40. Munsat, T. L. (1973) Congenital myopathies. In: The Striated Muscle (Pearson, C. M. \& Mostofi, F. K., eds.) p. 442, Williams and Wilkins, Baltimore.

41. Spiro, A. J., Shy, G. M. \& Gonatas, N. K. (1966) Myotubular myopathy. Arch. Neurol. 14, 1-14.

42. Mallory, F. B. (1911) Cirrhosis of the liver: Five different types of lesions from which it may arise. Bull. Johns Hopkins Hosp. 22, 69-74.

43. Yokoo, H., Minick, O. T., Bath, E. \& Kent, G. (1972) Morphologic variants of alcoholic hyalin. Am. J. Pathol. $69,25-32$.

44. Vyberg, M. \& Leth, P. (1991) Ubiquitin: an immunhistochemical marker of Mallory bodies and alcoholic liver disease. Acta Pathol. Microbiol. Immunol. Scand. (APMIS)-Suppl. 23, 46-52.

45. Osborn, M. \& Weber, K. (1989) Keratins, transglutaminase, and Mallory-bodies - the really insoluble stuff. Lab. Invest. 61, 585-587.

46. Preisegger, K. H., Zatloukal, K., Spurey, K. \& Denk, H. (1991) Changes of cytokeratin filament organization in human and murine Mallory body-containing livers as revealed by a panel of monoclonal antibodies. Liver 11 , $300-309$.

47. Galloway, P. G. \& Perry, G. (1991) Tropomyosin distinguishes lewy bodies of Parkinson disease from other neurofibrillary pathology. Brain Res. 541, 347-349.

48. Jellinger, K. (1990) New developments in the pathology of Parkinson's disease. Adv. Neurol. 53, 1-16.

49. Crowther, R. A. (1990) Structural aspects of pathology in Alzheimer's disease. Biochim. Biophys. Acta 1096, 1-9.

50. Anderton, B. H., Brion, J. P., Flament-Durand, J., Haugh, M. C., Kahn. J. \& Miller, C. C. (1987) Neurofibrillary tangles and the neuronal cytoskeleton. J. Neurol. Transm. Suppl. 24, $191-219$.

51. Finley, D. \& Chau, V. (1991) Ubiquitination. Annu. Rev. Cell Biol. 7, 25-69.

52. Mayer, R. J., Arnold, J., Laszlo, L., Landon, M. \& Lowe, J. (1991) Ubiquitin in health and disease. Biochim. Biophys. Acta $1080,141-157$.

53. Rechsteiner, M. (1991) Natural substrates of the ubiquitin proteolytic pathway. Cell 66, 615-618.

54. Denk, H., Franke, W. W., Kerjaschki, D., Schmid, E., Osborn, M. \& Weber, K. (1979) Experimental Mallory bodies, new finding on evolution, structure and pathologic significance. In: The Liver, Quantitative Aspects of Struc- ture and Function (Preising, R., Paumgartner, G. \& Bircher, J., eds.) p. 43. Karger, Basel.

55. Philips, M. J. \& Satir, P. (1988) The cytoskeleton of the hepatocyte: organization, relationships, and pathology. In: The Liver, Biology' and Pathobiology, 2nd ed. (Arias, I. M., Jakoby, W. B., Popper, H., Schachter, D. \& Shafritz, D. A., eds.) New York: Raven Press. pp. 11-27.

56. Irie, T., Benson, N. C. \& French, S. W. (1982) Relationship of Mallory bodies to the cytoskeleton of hepatocytes in griseofulvin-treated mice. Lab. Invest. 47, 336-345.

57. Reichen, J. \& Simon, F. R. (1988): Cholestasis. In: The Liver, Biology' and Pathobiology, 2nd ed. (Arias, I. M., Jakoby, W. B., Popper, H., Schachter, D. \& Shafritz, D. A., eds.) New York: Raven Press. 1105-1124.

58. Grundke-Iqbal, I. \& Iqbal, K. (1989) Neuronal cytoskeleton in the biology of Alzheimer disease. Prog. Clin. Biol. Res. 317, 745-753.

59. Anderton, B. H. (1988) Alzheimer's disease, helical filaments and the cytoskeleton. Nature 335, 497-498.

60. Lach, B., Sikorska, M., Rippstein, P., Gregor, A., Staines, W. \& Davie, T. R. (1991) Immunelectron microscopy of Rosenthal fibers. Acta Neuropathol. Berl. 81, 503- 509.

61. Traub, P. (1985) Intermediate Filaments. A Review. Springer-Verlag Heidelberg.

62. Bennett, V. (1989) The spectrin-actin junction of erythrocyte membrane skeletons. Biochim. Biophys. Acta 988, $107-121$.

63. Lazarides, E. \& Woods, C. (1989) Biogenesis of the red blood cell membrane-skeleton and the control of erythroid morphogenesis. Annu. Rev. Cell Biol. 5, 427-452.

64. Byers, T. J. \& Branton, D. (1985) Visualization of the protein associations in the erythrocyte membrane skeleton. Proc. Natl. Acad. Sci. USA 82, 6153-6157.

65. Liu, S. C., Derick, L. H. \& Palek, J. (1987) Visualization of the hexagonal lattice in the erythrocyte membrane skeleton. J. Cell Biol. 104, 527-536.

66. Liu, S. C., Derick, L. H., Duquette, M. A. \& Palek, J. (1989) Separation of the lipid bilayer from the membrane skeleton during discocyte-echinocyte transformation of human erythrocyte ghosts. Europ. J. Cell Biol. 49, 358365.

67. Whitfield, C. F., Follweiler, J. B., Lopresti-Morrow, L. \& Miller, B. B. (1991) Deficiency of alpha-spectrin synthesis in burst-forming units-erythroid in lethal hereditary spherocytosis. Blood 78, 3043-3051.

68. Coetzer, T. Lawler, J., Pochal, J. T. \& Palek, J. (1987) Molecular determinants of clinical expression of hereditary elliptocytosis. Blood 70, 766-772.

69. Lux, S. E. \& Becker, P. S. (1989) Disorders of the red cell membrane skeleton: hereditary spherocytosis and hereditary elliptocytosis. In: The Metabolic Basis of Inherited Disease. 6. edit. (Scriver, C. R., Beaudet, A. L., Sly, W. S. \& Valle, D., eds.) McGraw Hill New York. pp. 23672408.

70. Epstein jr., E. H. (1992) Molecular genetics of epidermolysis bullosa. Science 256, 799-804.

71. Editorial (1992) Epidermolysis bullosa simplex: A disorder of keratin. Lancet 339, 29-30.

72. Kitajima, Y., Inone, S. \& Yaoita, H. (1989) Abnormal organization of keratine intermediate filaments in cultured keratinocytes of epidermolysis bullosa simplex. Arch. Dermatol. Res. 281, 5-10.

73. Monaco, A. P. \& Kunkel, L. M. (1987) A giant locus for the Duchenne and Becker muscular dystrophy gene. Genetics 3, 33-40.

74. Hoffman, E. P., Brown jr., R. H. \& Kunkel, L. M. (1987) Dystrophin: The protein product of the Duchenne muscular dystrophy locus. Cell 51, 919-928.

75. Monaco, A. P. (1989) Dystrophin, the protein product of the Duchenne/Becker muscular dystrophy gene. TIBS 14 , $412-414$. 
76. Koenig. M., Hoffman, E. P., Bertelson, C. J., Monaco, A. P., Feener, C. \& Kunkel, L. M. (1987) Complete cloning of the DMD cDNA and preliminary genomic organisation of the DMD gene in normal and affected individuals. Cell 50, 509-517.

77. Hoffman, E. P. (1989) Human molecular genetics and the elucidation of the primary biochemical defect in Duchenne muscular dystrophy. Cell Mot. Cytoskelet. 14, 163-168.

78. Koenig, M. \& Kunkel, L. M. (1990) Detailed analysis of the repeat domain of dystrophin reveals four potential hinge segments that may confer flexibility. J. Biol. Chem. $265,4560-4566$.

79. Zubrzycka-Gaarn, E. E., Bulman, D. E., Karpati, G., Burghes, A. H. M., Belfall, B., Klamut, H. J., Talbot, J., Hodges, R. S., Ray, P. N. \& Worton, R. G. (1988) The Duchenne muscular dystrophy gene product is localized in sarcolemma of human skeletal muscle. Nature 333 , 466-469.

80. Miranda, A. F., Bonilla, E., Martucci, G., Moraes, C. T., Hays, A. P. \& Dimauro, S. (1988) Immunocytochemical study of dystrophin in muscle cultures from patients with Duchenne muscular dystrophy and unaffected control patients. Am. J. Pathol. 132, 410-416.

81. Ervasti, J. M., Ohlendieck, K., Kahl, S. D., Gaver, M. G. \& Campbell, K. P. (1990) Deficiency of a glycoprotein component of the dystrophin complex in dystrophic muscle. Nature 345, 315-319.

82. Yoshida. M. \& Ozawa, E. (1990) Glycoprotein complex anchoring dystrophin to sarcolemma. J. Biochem. 108, $748-752$.

83. Mandel, J. L. (1989) The gene and its product. Nature $339,584-586$.

84. Lidow, H. G. W., Byers, T. J., Watkin, S. C. \& Kunkel, L. M. (1990) Localization of dystrophin to postsynaptic regions of central nervous system cortical neurons. Nature 348, 725-728.

85. Michalak, M. \& Zubrzycka-Gaarn, E. (1990) Identification of dystrophin in cardiac sarcolemmal vesicles. Biochem. Biophys. Res. Comm. 169, 565-570.

86. Tanaka, H. \& Ozawa, E. (1990) Expression of dystrophin mRNA and the protein in the developing rat heart. Biochem. Biophys. Res. Comm. 172, 824-829.

87. Ferlini, A., Ansaloni, L., Nobile, C. \& Forabosco, A. (1990) Molecular analysis of the Rett-syndrome using cDNA synapsin I as probe. Brain Dev. 12, 136-139.

88. DeGennaro, L. J., McCaffery, C. A., Kirchgassner, C. U., Yang Feng, T. L. \& Franck, U. (1987) Molecular analysis of synapsin I, a candidate gene for Rett syndrome. Brain Dev. 9, 469-474.

89. Valtorta, F., Benfenati, F. \& Greengard, P. (1992) Structure and function of the synapsins. J. Biol. Chem. 267, 71957198.

90. Benfenati, F., Valtorta, F. \& Greengard, P. (1991) Computer modeling of synapsin I binding to synaptic vesicles and $\mathrm{F}$-actin. Implications for regulation of neurotransmitter release. Proc. Natl. Acad. Sci. U.S. A. 88, 575579.

91. Deary, I. J. \& Whalley, L. J. (1988) Recent research on the causes of Alzheimer's disease. Brit. Med. J. 297, 807810.

92. Holtzman, D. M. \& Mobley, W. C. (1991) Molecular studies in Alzheimer's disease. TIBS 16, 140-144.

93. Bancher, C., Grundke-Iqbal, I., Iqbal, K., Fried, V. A., Smith, H. T. \& Wisniewski, H. M. (1991) Abnormal phosphorylation of tau precedes ubiquitination in neurofibrillary pathology of Alzheimer disease. Brain Res. 539, $11-18$.

94. Iqbal, K., Grundke-Iqbal, I., Zaidi, T., Mertz, P. A., Wen, G. Y., Shaikh, S. S., Wisniewski, H. M., Alafuzoff, I. \& Winblad, B. (1986) Defective brain microtubule assembly in Alzheimer's diseasc. Lancet $I I, 421-426$.
95. Iqbal, K., Grundke-Iqbal, I. \& Wisniewski, H. M. (1987) Alzheimer's disease, microtubule and neurofilament proteins, and axoplasmic flow. Lancet $I, 102$.

96. Roder, H. M. \& Ingram, V. M. (1991) Two novel kinases phosphorylate Tau and the USP site of heavy neurofilament subunits in high stoichiometric ratio. J. Neurosci. 11, 3325-3343.

97. Koch, P. J., Walsh, M. J., Schmelz, M., Goldschmidt, M. D., Zimbelmann, R. \& Franke, W. W. (1990) Identification of desmoglein, a constitutive desmosomal glycoprotein, as a member of the cadherin family of cell adhesion molecules. Europ. J. Cell Biol. 53, 1-12.

98. Nilles, L. A., Parry, D. A., Powers, E. E., Angst, B. D., Wagner, R. M. \& Green, K. J. (1991) Structural analysis and expression of human desmoglein: A cadherin-like component of the desmosome. J. Cell Sci. 99, 809-821.

99. Buxton, R. S. \& Magee, A. I. (1992) Structure and interactions of desmosomal and other cadherins. Sem. Cell Biol. 3, 157-167.

100. Amagai, M., Klaus-Kovtun, V. \& Stanley, J. R. (1991) Autoantibodies against a novel epithelial cadherin in pemphigus vulgaris, a disease of cell adhesion. Cell 29, 869877.

101. Ouyang, P. \& Sugrue, S. P. (1992) Identification of an epithelial protein related to the desmosome and intermediate filament network. J. Cell Biol. 118, 1477-1488.

102. Thacher, S. M. \& Hefti, P. L. (1991) Characterization of 230-kD bullous pemphigoid antigen associated with the detergent soluble fraction of cultured keratinocytes. J. Invest. Dermatol. 96, 139-143.

103. Zhu, X. J., Niimi, Y. \& Bystryn, J. C. (1990) Identification of a $160-\mathrm{kD}$ molecule as a component of the basement membrane zone and as a minor bullous pemphigoid antigen. J. Invest. Dermatol. 94, 817-821.

104. Tanaka, T., Parry, D. A., Klaus-Kovtun, V., Steinert, P. M. \& Stanley, J. R. (1991) Comparison of molecularly cloned bullous pemphigoid antigen to desmoplakin I confirms that they define a new family of cell adhesion junction plaque proteins. J. Biol. Chem. 266, 12555-12559.

105. Popper, H. \& Schaffner, H. (1970) Pathophysiology of cholestasis. Human Pathol. 1, 1-24.

106. Phillips, M. J., Oda, M., Mak, E., Fisher, M. M. \& Jeejeebhoy, K. N. (1975) Microfilament dysfunction as a possible cause of intrahepatic cholestasis. Gastroenterology $69,48-58$.

107. Montesano, R., Gabbiani, G., Perrelet, A. \& Orci, L. (1976) In vivo induction of tight junction proliferation in rat liver. J. Cell Biol. 68, 793-798.

108. Weber, A. M., Tuchweber, B., Yousef, I. M., Brochu, T. Turgeon, C., Gabbiani, G., Morin, C. L. \& Roy, C. C. (1981) Severe familial cholestasis in North American Indian children. A clinical model of microfilament dysfunction. Gastroenterology 81, 653-662.

109. Tuchweber, B., Roy, S., Desroches, S., Yousef, I. M., Giequaud, C., Weber, A. M. \& Lorenger, A. (1990) Effect of bile acids on actin polymerisation in vitro. Life Sci. 47 , 1299-1307.

110. Oshio, C. \& Philips, M. J. (1981) Contractility of bile canaliculi: Implications for liver function. Science 212 , $1401-1402$.

111. Dubin, M., Maurice, M., Feldman, G. \& Erlinger, S. (1980) Influence of colchicine and phalloidin on bile secretion and hepatic ultrastructure in the rat. Gastroenterology 79, 646-654.

112. Erlinger, S. (1990) Recent concepts in bile formation and cholestasis. Recent Prog. Med. 81, 387-391.

113. Hofmann, A. F. (1990) Bile acid secretion, bile flow and biliary lipid secretion in humans. Hepatology $12,17 \mathrm{~S}-$ 22S.

114. Paz Marzolo, M., Rigotti, A. \& Nervi, F. (1990) Secretion of biliary lipids from the hepatocyte. Hepatology 12, $134 \mathrm{~S}-141 \mathrm{~S}$. 
115. Kwiatkowski, D. J., Methl, R., Izumo, S., Nadal-Dinard, B. \& Yin, H. L. (1988) Muscle is the major source of plasma gelsolin. J. Biol. Chem. 263, 8239-8243.

116. Smith, D. B., Janmey, P. A., Sherwood, J. A., Howard, R. J. \& Lind, S. E. (1988) Increased plasma gelsolin levels in patients with plasmodium falciparum malaria: A consequence of hemolysis. Blood 72, 214-218.

117. Smith, D. B., Janmey, P. A. \& Lind, S. E. (1988) Circulating actin-gelsolin complexes following oleic acid-induced lung injury. Am. J. Pathol. 130, 261 - 267.
118. Aurell, A., Rosengren, L. E., Karlsson, B., Olsson, J. E., Zbornikova, V. \& Haglid, K. B. (1991) Determination of S-100 and glial fibrillary acid protein concentrations in cerebrospinal fluid after brain infarction. Stroke 22, 1254-1258.

119. Massaro, A. R., Scivoletto, G., Tonalli, P. (1990) Cerebrospinal fluid markers in neurological disorders. Ital. J. Neurol. Sci. I1, 537-547.

Prof. Dr. D. Kunze Institut für Pathologische und Klinische Biochemie der Charité Schumannstraße 20/22

D-10117 Berlin

Germany 
